
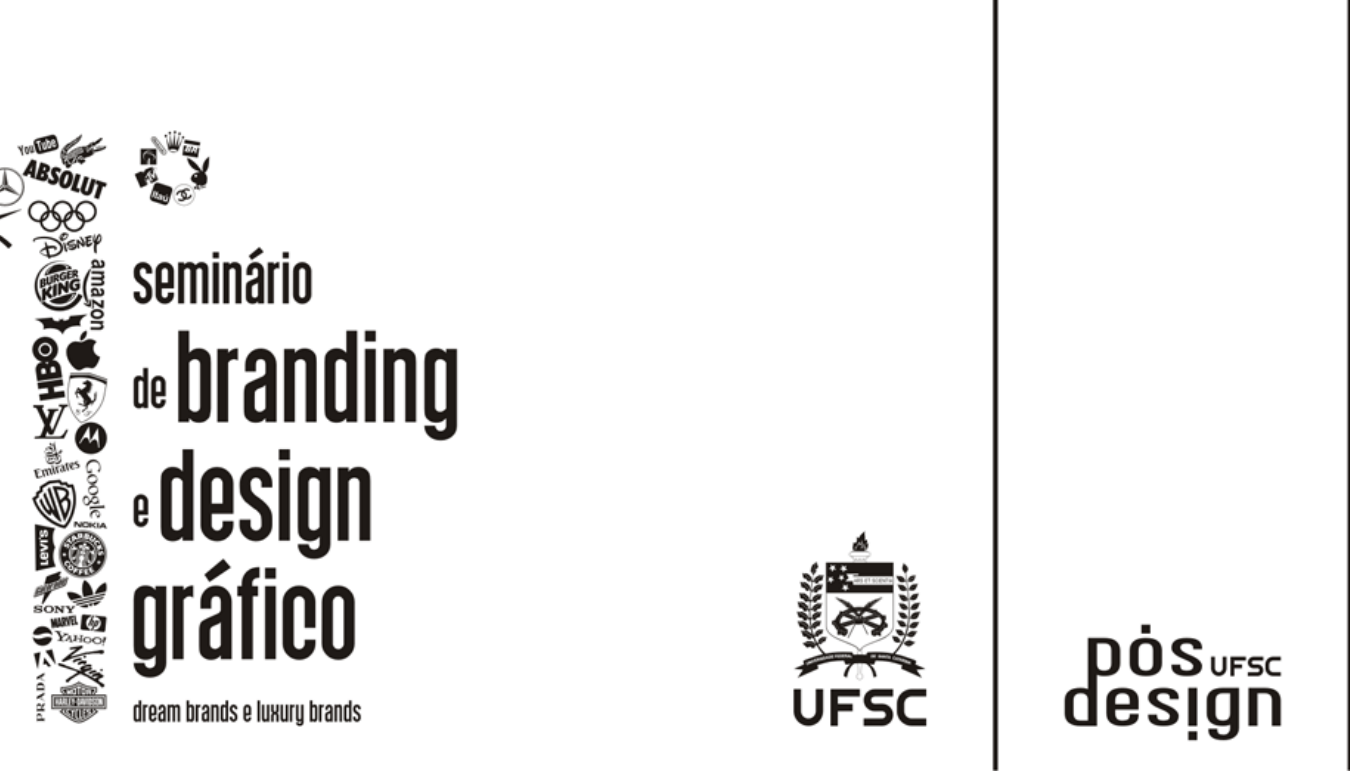

LOGO

\title{
Branding e o processo criativo do desenvolvimento de marcas
}

Branding and the creative processs of the development of brands

ADORNO, Luciano; aluno especial do programa de Pós-Gradução em Design e Expressão Gráfica; Universidade Federal de Santa Catarina - UFSC

adorno@horasc.com.br

\section{Resumo}

O presente estudo descreve uma proposta de processo para criação de marcas com ênfase em branding. A partir de autores como AAKER, ALENCAR, FRASCARA, GOMEZ, MUNARI, OSTROWER e WURMAN, busca possibilitar uma sistematização, visualização e entendimento do branding e da criatividade, com a finalidade de reforçar a eficácia deste processo para a geração de novas soluções.

Palavras Chave: branding, a priori, processo criativo

\section{Abstract}

The present study describes a proposal of process for creation of brands with emphasis in branding. Starting from of authors as ALENCAR, FRASCARA, GOMEZ, MUNARI, OSTROWER and WURMAN, search to permit a systematization, visualization and understanding of the branding and of the creativity, with the finality of the to reinforce the efficacy this process to the generation of new solutions.

Keywords: branding, a priori, creative process. 


\section{Branding}

O trabalho de um designer gráfico, de modo geral, compreende a busca de soluções, considerando a otimização no processo de produção e qualidade no produto final, segundo FRASCARA (2005, p.77) com métodos dirigidos a reduzir e melhorar a eficácia dos diversos passos no processo de design. Então, o designer, é um solucionador de problemas; um projetista que a partir da criatividade, busca gerar propostas relativamente rápidas e de qualidade. Contudo, este estudo se limitará a abordar "branding e processo criativo do desenvolvimento de marcas", enfatizando três aspectos: a priori, criatividade e soluções. Escrever sobre isto, tem como objetivo possibilitar a sistematização, visualização e entendimento da ocorrência do branding e da criatividade, com a finalidade de verificar a eficácia deste processo para a geração de novas soluções.

Nisto, considerando a idéia de que: "O branding não é um produto, nem um serviço. É uma postura empresarial orientada pela 'Marca' e pela sua gestão, que liga emocionalmente a empresa aos clientes, e tem como base 'Inovação'." (SARAIVA, 2008). E conforme AAKER (2002) afirma, são os fatores intangíveis como a imagem, o prestígio, a cultura que transmite e a relação que estabelece com seus clientes que torna uma marca autêntica.

Além disto, como em os “4P's do Design” de GOMEZ (2004), não pretende-se fazer algo definitivo, único ou exclusivo. Apenas compartilhar e verificar a validade de um processo que é aberto a diversas possibilidades de evolução e, colaborativamente, pode auxiliar outros designers a trabalharem com criação ou à geração de novas e melhores propostas.

\section{Criatividade e a priori}

Diferente de MUNARI (1998, p.44), não se acredita na diferença entre criatividade e idéia intuitiva, a qual ele julga como "modo artístico-romântico de resolver um problema". Pois, ao se ter uma idéia, provavelmente, ela não tenha surgido "do nada"; ela faz parte de uma série de associações intuitivas. Segundo OSTROWER (2007, p.9) as formas de percepção não são gratuitas, nem os relacionamentos se estabelecem ao acaso. As idéias vêm do conhecimento de seu autor; do "a priori" ou bagagem cultural, o qual a teoria da comunicação conceitua como repertório; que comporta "...tudo que o homem sabe, os conhecimentos, as conjecturas, as propostas, as dúvidas, tudo o que ele pensa e imagina.” (COELHO, 2007, p.55). Logo, este é “...uma espécie de vocabulário, de estoque de signos conhecidos e utilizados por um indivíduo." (idem, idem, p.123).

A intuição está diretamente relacionada à inteligência criativa; ao conhecimento e à capacidade de associar. Seja associação de formas, de cheiros, ou todas outras percepções que os sentidos possibilitem, mas principalmente à capacidade de ver relações onde poucos vêm. GOMEZ (2004) reforça esta idéia, a partir da tese de que "...o pensamento humano não é linear e imprescinde de estrutura fechada para obter resultados organizados."

A criatividade pode valorizar aspectos intuitivos, ligados à percepção, sensibilidade ou mesmo à loucura. Sobre isto, OSTROWER (2007, p.10) argumenta que "Os processos de criação ocorrem no âmbito da intuição. Embora integrem [...] toda experiência possível ao indivíduo, também ao racional, trata-se de processos essencialmente intuitivos." Como prova, cabe citar a genialidade de Van Gogh e o universo onírico de Salvador Dali, os quais valorizavam o intuitivo 
e tinham processos próprios para a construção de suas obras. Contudo, acredita-se que os processos de criação, também ocorram conforme apresenta MUNARI (1998); por coleta e análise de dados após "problema, definição e componentes", porém não de modo exclusivo.

A criatividade então, faz uso do "a priori", e isto não significa que para se desenvolver algo criativo é preciso saber tudo, mas que a cultura, o conhecimento, a experiência, a técnica, e as informações que se adquire, são determinantes para uma melhor e mais rápida solução criativa. ALENCAR (1996, p.28) considera que "todo ser humano é criativo [...] dependendo sobretudo das condições de educação e de sua socialização, que possibilitam um maior ou menor desenvolvimento do potencial criativo".

Consecutivamente, quanto maior o "a priori", maior as possibilidades de solução. E, como sugere WURMAN (1991) no livro Ansiedade de Informação, não é preciso saber tudo; basta saber encontrar a informação necessária, tendo em vista ser impossível assimilar todo o volume de informação produzida diariamente. $\mathrm{O}$ "a priori" é determinante para saber o que procurar, como e onde encontrar estas informações e se poder desviar das que não se tem interesse.

\section{Processo criativo}

Durante este processo, o "a priori" tem papel fundamental, onde as escolhas dependerão desta aparentemente dicotômica inteligência intuitiva e racional. Na etapa seguinte, o "a priori" e o branding são responsáveis pela geração de idéias criativas possibilitando o pensamento associativo em busca de novas soluções. Seja através de uma palavra ou de uma imagem, pois concomitantemente, realiza-se brainstormings e esboça-se alguns modelos de encontro aos valores que se deseja transmitir como diferencial de marca, caracterizando-se como uma ação de branding junto ao processo criativo. Nesta etapa, podem ocorrer "insights". Em relação a isto, ALENCAR (1996, p.28), comenta sobre lampejos: “...podem ser breves ou ocorrer de repente, são freqüentes e todos nós já passamos por situações que atestam sua existência." Além disto, podem surgir novos problemas ou integração das idéias. FRASCARA (2005, p.78) reconhece que apesar de não ser aconselhável começar a desenhar prematuramente a solução de um problema, sempre existe um salto intuitivo-criativo entre a informação obtida e sua interpretação visual. Ainda nesta etapa, há a preocupação de torná-la inteligível ao público.

Além da relevância da ênfase no diferencial intangível, AAKER (2008) recomenda para o desenvolvimento de uma marca forte, tarefas essenciais: a identidade da marca; a arquitetura; uma organização com um processo e modelo de planejamento para conduzir a marca e seus produtos; um programa de comunicação que vincule a marca ao estilo de vida de seus clientes.

No processo de criação da marca, muitas vezes encontra-se mais de uma solução. Geralmente não se satisfaz com a primeira. Por isso, os esboços são de grande relevância, pois a idéia pode parecer "fraca", mas quando visualiza-se, pode-se ter opinião oposta. Diante de tantos modelos, surge então a dúvida. É necessária uma avaliação e escolha. Caso aconteça de não se o chegar a um consenso, pede-se uma segunda opinião para a escolha. Escolhido o esboço, faz-se a arte-final. Ao término da criação, registra-se os aspectos tangíveis e intangíveis com os quais a marca foi solucionada, para reutilizá-los e ampliar o "a priori" para agir em situações que exijam novas soluções. 


\section{Considerações finais}

O branding e o processo criativo de marcas os quais inicialmente acreditava-se ser cíclico, mostrou-se linear até o núcleo "a priori" se ramificando no núcleo "criatividade", onde apresentou uma ordem não linear de acontecimentos no "processo criativo", resultando novamente em parcialmente linear, retornando à cíclica e ligando-se ao núcleo "soluções", gerando mais "a priori". Nisto, possibilitando uma visualização da complexidade do pensamento de um processo aparentemente simples, bem como um melhor entendimento de como funciona o branding associado ao processo de criação marcas, que estes podem ser melhorados, reduzindo etapas, mudando ordem destas e a partir de outros meios a definir.

Contudo, percebe-se que ao gerar mais "a priori", a partir do núcleo "soluções", corre-se o risco de desenvolver idéias que podem carecer de originalidade. E, considerando originalidade como uma das características da criatividade, pode-se não estar fazendo trabalhos tão criativos quanto se imagina ao reciclar algumas idéias reapresentando-as com novas roupagens. Sobre isto, COELHO (2007, p.128), diz que a imprevisibilidade é a medida da originalidade, sendo ocasionada pela complexidade da taxa de informação de uma mensagem.

Por outro lado, o "a priori" não é gerado exclusivamente destas soluções. Logo, neste caso, não há como criar algo totalmente não original; não criativo. COELHO (idem, p.129), também discorre sobre isto, considerando que a busca pelo novo absoluto "...é tão impossível quanto a renegação total de tudo quanto já foi anteriomente proposto.” Então, o processo de branding e criação de marca investigado, em princípio funciona, pode e deve ser melhorado e é digno de ser investigado mais profundamente com ênfase em aspectos relacionados à sua complexidade, criatividade, qualidade, público e todos os demais aspectos mencionados ao longo deste estudo.

\section{Referências}

AAKER, D. O ABC do valor da marca. Revista HSM Management, n 31, março-abril, 2002. Disponível em <http://www.hsm.com.br/hsmmanagement/edicoes/numero_31/abc_valor_marca> Acesso em: 25 mai. 2008.

ALENCAR, E. A gerência da criatividade. São Paulo: Makron Books, 1996.

COELHO, J. Semiótica, informação e comunicação. São Paulo: Perspectiva, 2007.

FRASCARA, J. Diseño gráfico y comunicacion. Buenos Aires: Ediciones Infinito, 2005.

GOMEZ, L. Os 4P's do design: uma proposta não linear de projeto. Tese (Doutorado em Engenharia de Produção) - Universidade Federal de Santa Catarina, Florianópolis, 2004.

MUNARI, B. Das coisas nascem as coisas. São Paulo: Martins Fontes, 1998.

OSTROWER, F. Criatividade e processos de criação. Petrópolis: Vozes, 2007. 
SARAIVA, C. A inovação e o branding. Disponível em

$<$ http://www.centralartigos.com/Negocios/marketing/a-inovacao-e-o-branding.html > Acesso em: 01 jul. 2008.

WURMAN, R. Ansiedade de informação. São Paulo: Cultura Editores Associados, 1991. 